\title{
BAGAIMANA KEAMANAN PANGAN, KUALITAS MAKANAN DAN CITRA MEREK MEMPENGARUHI MINAT BELI ULANG
}

\author{
Hanjaya Siaputra \\ Program Manajemen Perhotelan, Fakultas Bisnis dan Ekonomi, Universitas Kristen Petra, \\ Jl. Siwalankerto 121-131, Surabaya 60236, Indonesia. \\ Email: tjunhan@petra.ac.id
}

\begin{abstract}
Abstrak
Lika-liku bisnis makanan dan minuman tidak selalu semanis yang dibayangkan. Kejadian keracunan makanan dan minuman masih sering membayangi geliat usaha di bidang yang satu ini. Ketika tragedi seperti ini terjadi, restoran harus berusaha keras menumbuhkan minat beli ulang konsumen atas produk yang ditawarkan. Tujuan dari penelitian ini adalah untuk mengetahui pengaruh keamanan pangan, kualitas makanan dan citra merek terhadap minat beli ulang konsumen restoran "XYZ" dengan kepuasan konsemen sebagai mediator. Penelitian ini menggunakan pendekatan kuantitatif kausal dengan penyebaran kuesioner kepada 146 responden yang pernah mengkonsumsi produk restoran "XYZ". Data yang terkumpul dianalisis dengan Partial Least Square. Dari hasil analisa data yang dilakukan, terbukti adanya pengaruh yang positif dan signifikan antara keamanan pangan, kualitas makanan, citra merek, dan kepuasan konsumen terhadap minat beli ulang. Dalam penelitian ini juga terbukti bahwa kepuasan konsumen dapat berperan sebagai mediator terhadap minat beli ulang.
\end{abstract}

Kata kunci: Keamanan pangan, kualitas makanan, citra merek, kepuasan konsumen, minat beli ulang.

\begin{abstract}
The twists and turns of the food and beverage business are not always as sweet as one might imagine. Incidents of food and beverage poisoning still often overshadow the stretching of businesses in this industry. When a tragedy like this occurs, restaurants must try hard to foster consumer repurchase intention in the products offered. The purpose of this study was to determine the effect of food safety, food quality and brand image on consumer repurchase intention in "XYZ" restaurant consumers with customer satisfaction as a mediator. This study uses a causal quantitative approach by distributing questionnaires to 146 respondents who have consumed "XYZ" restaurant products. The data was analyzed using Partial Least Square. From the results of the data analysis, it was confirmed that there was a positive and significant influence between food safety, food quality, brand image, and consumer satisfaction on repurchase intention. In this study, it is also showed that customer satisfaction can act as a mediator of repurchase intention.
\end{abstract}

Keywords: Food safety, food quality, brand image, consumer satisfaction, repurchase intention.

\section{PENDAHULUAN}

Pertumbuhan bisnis makanan dan minuman semakin berkembang pesat. Salah satunya menciptakan pangsa pasar makanan sehat yang berbahan utama sayuran organik. Sayangnya, terkadang pertumbuhan bisnis tidak selalu melalui jalan yang mulus. Salah satunya restoran "XYZ" yang di awal kuartal pertama tahun 2019 lalu harus menghadapi fakta pahit dimana terdapat kasus keracunan makanan pada beberapa puluh konsumennya (JawaPos.com, 2019, April 4; Wijayanto, 2019a). Setelah kejadian tersebut, pihak restoran "XYZ" menyadari bahwa adalah penting untuk senantiasa menjaga keamanan makanan tetap terpelohara dengan baik. Serangkaian kebijakan diambil oleh pihak manajemen untuk meningkatkan kulitas makanan yang disajikan di restoran "XYZ". Tidak ketinggalan juga kampanye pemasaran melalui berbagai kanal pemasaran yang dimiliki. Hal tersebut bertujuan untuk meningkatkan citra merek restoran "XYZ" yang sempat terpuruk karena kejadian keracunan tersebut. Berkat usaha keras manajemen dan staf yang ada di garis depan, perlahan namun pasti kepercayaan konsumen mulai tumbuh, kepuasan 
konsumen meningkat dan konsumen mulai kembali melakukan pembelian di restoran "XYZ". Rangkaian perbaikan yang dilakukan oleh restoran "XYZ" bertujuan untuk membangun komunitas untuk hidup sehat. Bagi restoran "XYZ" adalah pencapaian terbesar untuk mampu memberi akses terhadap makanan sehat kepada semua orang, tidak hanya kalangan tertentu, (Wijayanto, 2019b)

Keamanan pangan merupakan serangkaian standar yang mengatur cara mencegah, memilah, serta mengendalikan bahaya pada makanan (Teixeria \& Sampaio, 2013). Menurut ISO 22000 dalam (Praxiom Research Group Limited, 2019) hal penting dari keamanan pangan adalah makanan yang bersih dan kualitas makanan yang baik agar tidak menyebabkan penyakit pada konsumen, selama hal tersebut dapat dijalankan dengan baik, mulai dari persiapan hingga disajikan kepada konsumen, maka keselamatan jiwa konsumen akan terpelihara dengan baik juga.

Selain keamanan pangan, kualitas makanan juga merupakan hal yang penting dalam bisnis makanan. Kualitas makanan dapat dipengaruhi oleh karakteristik-karakteristik yang dimiliki oleh suatu hidangan dan dapat dirasakan oleh konsumen yang mengkonsumsinya (Atkins, dan Bowler, 2001). Dalam Namkung, \& Jang (2007), dijelaskan bahwa kualitas makanan terdiri dari berbagai karakteristik seperti presentasi, kelezatan, variasi menu, dan suhu hidangan. Selanjutnya, dari penelitian Rozekhi, et al., (2016) menyarankan bahwa kualitas makanan dapat diukur menggunakan kesegaran makanan, rasa, aroma, kandungan nutrisi, presentasi dan variasi makanan yang disajikan.

Dalam penelitian Andreani, Taniaji, \& Puspitasari (2012), dinyatakan bahwa citra merek berkontribusi memberikan kepuasan terhadap konsumen dengan mempengaruhi persepsi konsumen atas kualitas yang dimiliki produk atau jasa yang ditawarkan suatu perusahaan. Hal yang sama juga diutarakan oleh Aaker \& Biel (2009), yang menuturkan bahwa indikator yang dapat membentuk citra merek adalah citra perusahaan, citra pemakai dan citra produk itu sendiri. Ketika konsumen menyukai citra merek yang dimiliki oleh produk atau jasa dari sebuah perusahaan, maka hal tersebut dapat meningkatkan kepuasan konsumen.

Dari paparan di atas, peneliti ingin mengetahui pengaruh dari keamanan makanan, kualitas makanan, citra merek dan kepuasan konsumen terhadap minat beli ulang konsumen restoran "XYZ" di Surabaya.

\section{TINJAUAN PUSTAKA}

\section{Keamanan Pangan}

Menurut Murray, et al., (2017) menjelaskan bahwa dimensi keamanan pangan dapat diukur menggunakan indikator berikut ini:

\section{Kebersihan}

Restoran dituntut untuk mampu memastikan bahwa setiap karyawan telah mengikuti seluruh prosedur kebersihan seperti mencuci tangan menggunakan sabun dan membilas tangan dengan air bersih yang mengalir, mencuci tangan setelah memegang daging mentah, membersihkan permukaan meja kerja setelah mengolah daging mentah atau unggas dengan sabun kemudian dibilas dengan air bersih untuk kemudian disemport dengan cairan disinfektan).

\section{Pemisahan}

Restoran juga diwajibkan untuk menyajikan makanan dan minuman yang aman dan layak untuk dikonsumsi. Setiap karyawan bertanggung jawab atas tindakan pencegahan untuk menghindari kontaminasi silang saat menggunakan talenan untuk daging mentah dan makanan lainnya. Menyimpan produk siap makan dan setengah jadi secara terpisah juga menjadi salah satu contoh tindakan memisahkan makanan sesuai prosedur.

3. Pemasakan

Staf dapur wajib untuk memastikan daging yang dimasak sudah sesuai tingkat kematangannya dengan menggunakan termometer khusus daging.

4. Penyimpanan

Staf dapur diharuskan untuk segera menyimpan sisa makanan yang masih dapat digunakan kembali ke dalam lemari pendingin.dalam kurun waktu 2 jam setelah dimasak

5. Pengetahuan

Para penjamah makanan wajib mengetahui risiko yang terkait dengan telur mentah, susu yang tidak dipasteurisasi, daging olahan, dan sayuran segar. Pelatihan dan penyegaran berkala perlu dilakukan untuk memastikan bahwa setiap penjamah makanan memahami dan melaksanakan semua prosedur keamanan pangan yang baik. 


\section{Kualitas Makanan}

Dalam penelitian Rozekhi, et al (2016) memaparkan bahwa kualitas makanan dapat diukur menggunakan enam indikator berikut ini:

1. Rasa

Rasa dianggap menjadi atribut utama dalam makanan pada saat bersantap. Konsumen semakin paham akan citarasa yang dimiliki oleh makanan dan minuman yang dikonsumsi. Hal ini juga meningkatkan ekspektasi konsumen akan citarasa yang tinggi. Maka dari itu, rasa suatu makanan yang tersaji dalam restoran amat sangat penting. Inilah sebabnya rasa dipercaya dapat mempengaruhi kepuasan konsumen dan niat berperilaku di masa depan.

2. Kesegaran

Kesegaran makanan biasanya terkait dengan renyah, juicy, dan penampilannya. Studi sebelumnya mengungkapkan bahwa kesegaran makanan yang terkenal sebagai isyarat kualitas intrinsik yang penting (Péneau et al, 2006).

3. Aroma

Ketika hendak menyantap suatu hidangan, aroma yang dihasilkan dari makanan tersebut berperan penting dalam menentukan rasa makanan dan mampu memberikan sinyal kandungan gizi yang dikandung oleh makanan terhadap konsumen.

4. Presentasi

Pemaparan dalam jurnal Namkung dan Jang (2007) menyatakan bahwa presentasi mengacu pada teknik penyajian makanan yang dihias sedemikian rupa untuk menarik perhatian konsumen agar dapat memenuhi persepsi konsumen tentang kualitas hidangan yang disantap.

5. Kandungan nutrisi

Bagi konsumen yang mencari makanan yang lebih sehat, menggunakan bahan-bahan segar adalah berbicara tentang memilih makanan yang akan mengarah pada gaya hidup yang lebih sehat dan terus berlanjutan keberadaannya. Restoran yang beralih ke bahan-bahan yang lebih segar akan menuai hasilnya tidak hanya dalam melakukan hal yang benar, kesehatan konsumen, tetapi juga mengenai rasa

6. Variasi menu

Restoran harus mampu menyajikanberbagai menu yang variatif untuk konsumen karena konsumen memiliki berbagai latar belakang budaya, etnis, ekonomi, serta pendidikan. Itulah sebabnya konsumen memiliki preferensi makanan yang berbeda-beda. Variasi menu diperlukan untuk melayani beragam preferensi makan konsumen yang berbeda-beda.

\section{Citra Merek}

Dari penelitian Aaker \& Biel (2009), terdapat 3 indikator yang dapat membentuk citra merek, yaitu sebagai berikut:

1. Corporate Image (citra perusahaan)

Hal ini merupakan sekumpulan asosiasi yang dirasakan konsumen terhadap perusahaan yang membuat suatu barang atau jasa. Citra perusahaan ini meliputi kredibilitas, pelayanan, dan juga ketenaran perusahaan.

2. User Image (citra pemakai)

Citra pemakai merupakan sekumpulan asosiasi yang dirasakan oleh konsumen terhadap pemakai yang menggunakan suatu barang dan jasa. Hal ini meliputi gaya hidup atau kepribadian pemakai itu sendiri, serta status sosialnya.

3. Product Image (citra produk)

Citra produk adalah sekumpulan asosiasi yang dipersepsikan konsumen terhadap suatu barang atau jasa yang meliputi atribut dari produk, harga, manfaat bagi konsumen, serta jaminan atas kualitas yang dimiliki.

\section{Kepuasan Konsumen}

Kumar \& Bhatnagar (2017) menjelaskan bahwa dimensi customer satisfaction dapat diukur menggunakan keempat indikator berikut ini:

1. Tingkat kepuasan produk

Kepuasan terhadap makanan yang mampu diberikan oleh restoran serta mendapatkan nilai yang positif dari makanan tersebut merupakan aspek paling utama dalam industri restoran dalam meningkatkan kepuasan konsumen.

2. Rekomendasi

Konsumen yang puas dan senang sesudah mengkonsumsi makanan dari suatu restoran, biasanya merekomendasikan perusahaan tersebut ke orang lain.

3. Pemilihan kembali

Konsumen yang terpenuhi kebutuhannya setelah mengkonsumsi hidangan di suatu restoran cenderung kembali memilih restoran yang sama.

4. Kepuasan Keseluruhan

Kepuasan secara keseluruhan berasal dari penilaian konsumen secara keseluruhan terhadap produk atau layanan restoran dan reaksi emosional konsumen mengenai kemampuan pihak restoran untuk menyediakan layanan agar memenuhi kebutuhan dan juga keinginan Konsumen. 


\section{Minat Beli Ulang}

Membeli ulang adalah tindakan yang munculnya dari rasa keinginan, yang didasarkan pada kepercayaan suatu produk yang pernah dirasakan (Kusdyah, 2012). Tong dan Wong (2014) menjelaskan bahwa dimensi pembelian kembali dapat diukur menggunakan indikator berikut ini:

1. Konsumen berniat untuk membeli kembali Pernyatan konsumen setelah konsumen membeli makanan dan puas dan melakukan pembelian di lain waktu.

2. Pilihan pertama dalam membeli produk sejenis Pernyataan konsumen yang menyatakan membuat restoran menjadi pemilihan pertama bila ingin membeli suatu produk tertentu.

3. Konsumen berniat untuk membeli lebih sering di waktu yang akan datang

Pernyataan konsumen yang membeli produk restoran ini lebih banyak pada waktu yang akan datang.

\section{Hubungan Antara Keamanan Pangan Terha- dap Kepuasan Konsumen}

Berdasarkan hasil penelitian oleh (Herfangsyah \& Handoko, 2015) telah didapat hasil dimana keamanan pangan berdampak terhadap kepuasan konsumen. Dengan senantiasa menyajikan makanan yang bersih dan sehat kepada konsumen, konsumen bakal memberikan respon yang baik terhadap tingkat kepuasan konsumen, dimana hal esensial dari keamanan pangan adalah membuat makanan yang baik yang bebas dari kontaminasi selama proses persiapan sampai ke penyajian (Praxiom Research Group Limited, 2019). Masih dari penelitian yang sama dari Herfangsyah \& Handoko (2015), juga disebutkan bahwa keamanan pangan dari sisi kebersihan area tempat kerja dan peralatan yang digunakan merupakan hal yang juga diperhatikan oleh konsumen, dan menjadi penilaian yang mudah oleh karena selalu terlihat oleh konsumen tersebut. Maka dari itu, dirumuskan bahwa hipotesa pertama adalah:

H1: Keamanan pangan berpengaruh secara positif dan signifikan terhadap kepuasan konsumen.

\section{Hubungan Antara Kualitas Makanan Terha- dap Kepuasan Konsumen}

Penelitian oleh Fungai (2017), merumuskan adanya hubungan positif antara kualitas makanan terhadap kepuasan konsumen. Penelitian Ryu, Lee, \& Kim (2012) menegaskan kualitas makanan menjadi suatu hal yang penting sebagai prediktor kepuasan konsumendalam industri restoran. Hasil dari penelitian mendapatkan lima aspek kualitas makanan yang diadopsi melalui (Ryu, Lee, \& Kim, 2012), yaitu: makanan yang segar, lezat, bergizi, adanya berbagai item menu, dan aroma makanan yang menggugah selera. Rozekhi, et al (2016) memaparkan bahwa kualitas makanan dapat diukur menggunakan rasa, kesegaran, aroma, presentasi penyajian makanan, kandungan nutrisi serta variasi makanan. Oleh sebab itu, hipotesa kedua adalah:

H2: Kualitas makanan berpengaruh secara positif dan signifikan terhadap kepuasan konsumen.

\section{Hubungan Antara Citra Merek Terhadap Ke- puasan Konsumen}

Citra merek terdiri dari beberapa brand association dalam dimensinya. Dalam Andreani, Taniaji, dan Puspitasari (2012), brand association yang kuat dapat membuat citra merek yang kuat dan meningkatkan kepuasan konsumen. Selanjutnya, hasil dari penelitian tersebut juga menunjukkan bahwa citra merek memiliki hubungan yang positif signifikan dengan kepuasan konsumen. Maka dari itu, hipotesa ketiga dari penelitian ini adalah:

H3: Citra merek berpengaruh secara positif dan signifikan terhadap kepuasan konsumen

\section{Hubungan Antara Kepuasan Konsumen Ter- hadap Minat Beli Ulang}

Penelitian Mensah (2018) menegaskan bahwa kepuasan konsumen mempengaruhi minat beli kembali secara positif dan signifikan. Penelitian tersebut mendukung yang dinyatakan dalam penelitian yang menguji kerangka konseptual yang sama di bidang telekomunikasi oleh Srivastava \& K. Sharma (2013) yang menyatakan bahwa kepuasan konsumen mempengaruhi minat beli ulang dan mengurangi kemungkinan berpindah ke penyedia lain. Hubungan tersebut didukung juga oleh (Sentoso, 2019) dimana minat beli ulang yang signifikan terjadi ketika konsumen mendapat kepuasan atas barang atu jasa yang telah dibeli. Semakin tingginya kepuasan dari konsumen, semakin tinggi pula minat pembelian ulang oleh konsumen pada suatu perusahaan.

Berdasarkan hasil yang didapat dari penelitian terdahulu, maka diuraikan hipotesa keempat dari penelitian ini adalah:

H4: Kepuasan konsumen berpengaruh secara positif dan signifikan terhadap minat beli ulang sebagai mediator. 


\section{METODE PENELITIAN}

Penelitian ini menggunakan metode penelitian kuantitatif deskriptif dengan pendekatan kausal. Penelitian ini memiliki populasi yang tidak terbatas (infinite). Populasi penelitian ini ialah konsumen restoran "XYZ" di Surabaya. Metode pemilihan sampel yang digunakan pada penelitian ini adalah non-probability sampling. Kriteria sampel yang digunakan adalah konsumen restoran "XYZ" yang berusia lebih dari 17 tahun baik pria maupun wanita, pernah mengunjungi dan makan di restoran "XYZ" dalam kurun waktu 3 bulan terakhir (Januari-Maret 2020). Dalam penelitian ini, kuesioner didistribusikan secara daring. Kuesioner disusun menggunakan laman Google Form dan disebarkan melalui media sosial Line Messenger, WhatsApp, dan Instagram. Teknik analisa data dalam penelitian ini menggunakan perangkat lunak Smart PLS 3 dan menggunakan perangkat lunak SPSS 16 untuk mengolah pilot test. Mengadopsi teori The Ten Times Rule Method, dari 18 indikator yang ada, maka ditentukan bahwa jumlah minimum responden adalah 10 kali lipat jumlah indikator (Kock, \& Hadaya, 2018)., yakni sebanyak 180 responden. Penelitian ini menggunakan 146 jawaban responden yang valid dari 180 kuesioner yang didistribusikan secara daring, 34 jawaban responden tidak valid.

Dalam penelitian ini dilakukan analisa dengan 2 cara yaitu analisis deskriptif dan pengolahan data menggunakan metode partial least square dengan perangkat lunak SmartPLS 3. Data dari kuesioner menjalani 2 tahap pengujian validitas dan reliabilitas. Uji pertama adalah untuk mengetahui validitas dan reliabilitas instrumen dilakukan dengan perangkat lunak IBM SPSS Statistics. Hasil dari uji tersebut menunjukkan bahwa seluruh variabel memenuhi uji validitas Pearson correlation, sehingga semua indikator tersebut dapat digunakan dalam penelitian ini. Sedangkan, uji kedua dilakukan adalah uji validitas data yang dilakukan dengan perangkat lunak SmartPLS 3. Uji reliabilitas instrumen dilakukan dengan perangkat lunak IBM SPSS dan semua indicator dinyatakan reliabel.

\section{HASIL PENELITIAN DAN PEMBAHASAN}

\section{Analisis Deskriptif}

Mayoritas dari responden berjenis kelamin perempuan (82 orang), berumur 17-24 tahun (49 orang), tingkat pendidikan terakhir sarjana (61 orang), berprofesi sebagai pengusaha (98 orang) dari 146 responden. a) Validitas konvergen

Tabel 1. Nilai outer loading

\begin{tabular}{lccc}
\hline \multicolumn{1}{c}{ Variabel } & Indikator & $\begin{array}{c}\text { Skor Outer } \\
\text { Loading }\end{array}$ & Keterangan \\
\hline Keamanan Pangan & X1.1 & 0.665 & Valid \\
& X1.2 & 0.524 & Valid \\
& X1.3 & 0.553 & Valid \\
& X1.4 & 0.698 & Valid \\
Xualitas Makanan & X2.5 & 0.687 & Valid \\
& X2.2 & 0.781 & Valid \\
& X2.3 & 0.599 & Valid \\
& X2.4 & 0.814 & Valid \\
& X2.5 & 0.654 & Valid \\
Citra Merek & X2.6 & 0.721 & Valid \\
& X3.1 & 0.729 & Valid \\
Kepuasan & X3.2 & 0.754 & Valid \\
Konsumen & X3.3 & 0.830 & Valid \\
& Y1 & 0.863 & Valid \\
& Y2 & 0.800 & Valid \\
Minat Beli Ulang & Y3 & 0.790 & Valid \\
& Y4 & 0.780 & Valid \\
& Z1 & 0.828 & Valid \\
& Z2 & 0.741 & Valid \\
& Z3 & 0.802 & Valid \\
\hline
\end{tabular}

Berdasarkan tabel 1, dapat diketahui bahwa semua indikator memiliki nilai outer loading $>0,5$. Sehingga dapat disimpulkan bahwa hasil uji telah memenuhi syarat uji validitas konvergen.

b) Validitas diskriminan

Table 2. Nilai cross loading

\begin{tabular}{lrrrrrr}
\hline $\begin{array}{c}\text { Indika } \\
\text { tor }\end{array}$ & $\begin{array}{r}\text { Keaman- } \\
\text { an Pangan }\end{array}$ & $\begin{array}{c}\text { Kualitas } \\
\text { Makanan }\end{array}$ & $\begin{array}{c}\text { Citra } \\
\text { Merek Konsumen }\end{array}$ & $\begin{array}{c}\text { Kepuasan } \\
\text { Binat } \\
\text { Beli } \\
\text { Ulang }\end{array}$ \\
\hline X1.1 & $\mathbf{0 . 6 7 0}$ & 0.392 & 0.245 & 0.435 & 0.327 \\
X1.2 & $\mathbf{0 . 5 3 1}$ & 0.257 & 0.370 & 0.345 & 0.175 \\
X1.3 & $\mathbf{0 . 5 6 4}$ & 0.226 & 0.339 & 0.226 & 0.130 \\
X1.4 & $\mathbf{0 . 7 0 7}$ & 0.345 & 0.311 & 0.329 & 0.161 \\
X1.5 & $\mathbf{0 . 7 0 0}$ & 0.343 & 0.304 & 0.395 & 0.267 \\
X2.1 & 0.520 & $\mathbf{0 . 7 8 1}$ & 0.266 & 0.437 & 0.367 \\
X2.2 & 0.398 & $\mathbf{0 . 5 9 9}$ & 0.172 & 0.285 & 0.271 \\
X2.3 & 0.466 & $\mathbf{0 . 8 1 4}$ & 0.216 & 0.485 & 0.439 \\
X2.4 & 0.329 & $\mathbf{0 . 7 4 3}$ & 0.141 & 0.393 & 0.385 \\
X2.5 & 0.413 & $\mathbf{0 . 6 5 4}$ & 0.280 & 0.429 & 0.395 \\
X2.6 & 0.429 & $\mathbf{0 . 7 2 8}$ & 0.321 & 0.349 & 0.412 \\
X3.1 & 0.124 & -0.018 & $\mathbf{0 . 7 2 9}$ & 0.325 & 0.244 \\
X3.2 & 0.328 & 0.169 & $\mathbf{0 . 7 5 4}$ & 0.392 & 0.285 \\
X3.3 & 0.423 & 0.291 & $\mathbf{0 . 8 3 0}$ & 0.546 & 0.372 \\
Y1 & 0.469 & 0.456 & 0.512 & $\mathbf{0 . 8 6 3}$ & 0.662 \\
Y2 & 0.472 & 0.554 & 0.411 & $\mathbf{0 . 8 0 0}$ & 0.670 \\
Y3 & 0.488 & 0.436 & 0.465 & $\mathbf{0 . 7 9 0}$ & 0.630 \\
Y4 & 0.408 & 0.399 & 0.533 & $\mathbf{0 . 7 8 1}$ & 0.591 \\
Z1 & 0.383 & 0.461 & 0.392 & 0.739 & $\mathbf{0 . 8 2 8}$ \\
Z2 & 0.230 & 0.407 & 0.257 & 0.514 & $\mathbf{0 . 7 4 1}$ \\
Z3 & 0.275 & 0.363 & 0.293 & 0.589 & $\mathbf{0 . 8 0 2}$ \\
\hline
\end{tabular}


Berdasarkan tabel 2, dapat dilihat bahwa hasil pengukuran setiap indikator dalam penelitian ini telah memenuhi syarat validitas diskriminan. Oleh karena itu, dapat ditarik kesimpulan dari hasil tabel yang telah disajikan bahwa indikator-indikator dalam penelitian ini valid.

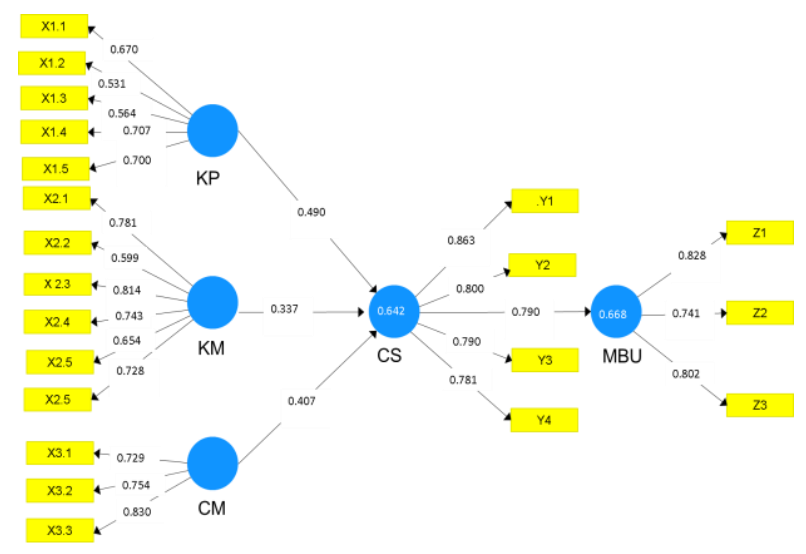

Gambar 1. Hasil uji validitas konvergen.

c) Uji Reliabilitas

Table 3. Nilai Reliabilitas

\begin{tabular}{|c|c|c|c|}
\hline Variabel & $\begin{array}{l}\text { Composite } \\
\text { Reliability }\end{array}$ & $\begin{array}{c}\text { Cronbach's } \\
\text { Alpha }\end{array}$ & $\begin{array}{c}\text { Average } \\
\text { Variance } \\
\text { Extracted } \\
(A V E)\end{array}$ \\
\hline Keamanan Pangan & 0.852 & 0.774 & 0.613 \\
\hline Kualitas Makanan & 0.806 & 0.717 & 0.522 \\
\hline Citra Merek & 0.883 & 0.823 & 0.590 \\
\hline Kepuasan Konsumen & 0.844 & 0.768 & 0.654 \\
\hline Minat Beli Ulang & 0.833 & 0.705 & 0.626 \\
\hline
\end{tabular}

Melalui hasil tabel 3 yang telah disajikan peneliti dapat mengetahui bahwa variabel keamanan pangan, kualitas makanan, harga dan kepuasan konsumen telah memiliki nilai composite reliability > 0,6 maka dapat dianggap bahwa setiap variabel yang telah memenuhi syarat composite reliability dan cronbach's alpha. Hal ini berarti kuesioner yang digunakan dalam penelitian ini dianggap reliabel, karena mampu menunjukkan tingkat konsistensi dan keakuratan yang baik.

\section{Evaluasi Inner Model}

Tabel 4. Nilai $R$-Square dan $Q$-square

\begin{tabular}{lcc}
\hline \multicolumn{1}{c}{ Variabel } & R-square & Q-square \\
\hline Kepuasan Konsumen & 0.642 & $1-(1-0.642) \times(1-$ \\
Minat beli ulang & 0.668 & $0.668)=0.8811$ \\
\hline
\end{tabular}

Dari hasil table 4 diketahui bahwa nilai $R$ square pada variabel kepuasan konsumen sebanyak 0.642 . Nilai $R$-square memiliki kegunaan untuk melihat seberapa besar pengaruh yang diberikan oleh variable independent terhadap variable dependen, sehingga nilai $R$ square dari penelitian diatas mempunyai makna bahwa keamanan pangan, kualitas makanan dan citra merek mempengaruhi $64.2 \%$ kepuasan konsumen restoran "XYZ" dan sebesar 35.8\% dipengaruhi oleh variable lainnya yang tidak diteliti. $R$-square pada variabel minat beli ulang mencapai sebanyak 0.668 hal ini menandakan dimana keamanan pangan, kualitas makanan, harga, dan kepuasan konsumen mempengaruhi $66.8 \%$ minat konsumen untuk melakukan pembelian ulang.

Berdasarkan tabel di atas, maka dapat dilihat bahwa nilai Q-square sebanyak 0.8811, yang memiliki arti bahwa model secara struktur dapat dikembangkan dalam penelitian dengan mempunyai ketepatan prediksi mencapai $88.11 \%$

\section{Uji Hipotesis}

Tabel 5. Uji t

\begin{tabular}{lcccc}
\hline \multicolumn{1}{c}{ Hipotesa } & $\begin{array}{c}\boldsymbol{P} \text { - } \\
\text { Value }\end{array}$ & $\begin{array}{c}\text { Koefisien } \\
\text { Estimasi }\end{array}$ & t-Statistic & Keterangan \\
\hline $\begin{array}{l}\text { Kepuasan } \\
\text { Konsumen } \\
\text { dipengaruhi }\end{array}$ & 0.011 & 0.490 & 7.553 & $\begin{array}{c}\text { Positif } \\
\text { oleh } \\
\text { keamanan } \\
\text { pangan }\end{array}$ \\
Kepuasan & 0.000 & 0.337 & 5.447 & Positifikan \\
$\begin{array}{l}\text { Konsumen } \\
\text { dipengaruhi } \\
\text { oleh kualitas }\end{array}$ & & & & \\
makanan & & & & Signifikan \\
$\begin{array}{l}\text { Kepuasan } \\
\text { Konsumen } \\
\text { dipengaruhi } \\
\text { oleh citra }\end{array}$ & 0.000 & 0.407 & 6.870 & \\
merek & & & & Positif \\
$\begin{array}{l}\text { Minat beli } \\
\text { ulang } \\
\text { dipengaruhi } \\
\text { oleh } \\
\text { kepuasan } \\
\text { konsumen }\end{array}$ & 0.000 & 0.790 & 26.105 & Positif \\
\hline & & & & Signifikan \\
& & & & \\
\hline
\end{tabular}

Dari sajian tabel 5 tersebut, dapat disimpulkan bahwa seluruh hipotesa bisa diterima. Karena nilai P-value < 0.05, sehingga hipotesa diterima. Selain itu nilai dari t-statistik dari seluruh hipotesa 
> 1.96 dapat disimpulkan memiliki pengaruh yang signifikan. Dan juga nilai dari koefisien estimasi dari seluruh hipotesa bernilai positif artinya setiap variabelnya berpengaruh positif.

\section{Pembahasan}

Berdasarkan hasil olah data yang telah dipaparkan di atas, terbukti bahwa variabel keamanan pangan mempunyai pengaruh secara positif dan signifikan terhadap kepuasan konsumen restoran 'XYZ". Hasil yang diperoleh ini sejalan dengan hasili penelitian Murray, et al., (2017) dan Herfangsyah \& Handoko (2015) yang juga membuktikan bahwa keamanan pangan berpengaruh terhadap kepuasan konsumen. Melihat data di atas, setiap peningkatan keamanan pangan yang dilakukan restoran "XYZ", maka meningkat pula kepuasan dari setiap konsumen yang makan di restoran "XYZ".

Data yang diperoleh juga menunjukkan bahwa kualitas makanan juga berpengaruh secara positif dan signifikan terhadap kepuasan konsumen. Hasil yang serupa juga dapat ditemukan pada penelitian Al-Tit (2015); Kumar dan Bhatnagar (2017); juga oleh. Fungai (2017). Pada penelitian-penelitian dahulu menjelaskan bahwa kepuasan konsumen salah satunya dipengaruhi oleh kualitas makanan. Hasil ini bisa diartikan bahwa responden beranggapan bahwa kepuasan yang di rasakan dipengaruh oleh kualitas makanan restotan "XYZ".

Data di atas juga menunjukkan pengaruh positif dan signifikan dari citra merek terhadap kepuasan konsumen. Dengan semakin kuatnya citra merek di benak konsumen, maka kepuasan konsumen juga akan semakin meningkat. Hasil penelitian ini konsisten dengan hasil penelitian Andreani, Taniaji, \& Puspitasari (2012) dan Lahap, Ramlib, Said, Radzid, \& Zain (2016) dimana citra merek berpengaruh positif signifikan terhadap kepuasan konsumen.

Pada pembahasan mengenai kepuasan konsumen, hasil penelitian ini membuktikan bahwa kepuasan konsumen atau konsumen dapat dipengaruhi secara signifikan dan positif pada minat dalam membeli kembali barang tersebut. Data yang diperoleh sejalan dengan hasil penelitian Fungai (2017) yang juga menyebutkan bahwa kepuasan konsumen berpengaruh paling dominan terhadap keputusan konsumen untuk membeli kembali produk tersebut. Hasil ini berarti menunjukan bahwa semakin tinggi kepuasan konsumen yang di rasakan responden maka semakin besar juga peluang responden untuk melakukan pembelian ulang di restoran "XYZ". Kepuasan konsumen digunakan sebagai variable mediator, karena untuk mencapai minat beli ulang. Berdasarkan hasil uji lajur, dapat diketahui bahwa kepuasan konsumen mendapatkan pengaruh sebesar 64,2\% dari kualitas makanan, kualitas layanan, dan citra merek. Sedangkan, minat beli ulang mendapatkan pengaruh $66,8 \%$ dari kepuasan konsumen. Hal ini menunjukkan efek mediasi dari kepuasan konsumen dimana $64,2 \%$ dari pengaruh yang diberikan kepuasan konsumen terhadap minat beli ulang datang dari variabelvariabel independen yang mempengaruhinya. Dengan demikian, dapat disimpulkan bahwa kepuasan konsumen dapat menjadi mediator dalam penelitian ini.

\section{SIMPULAN DAN SARAN}

\section{Kesimpulan}

Berdasarkan. hasil penelitian dimana telah dilakukan oleh peneliti maka peneliti dapat menarik kesimpulan adalah sebagai berikut:

1. Keamanan pangan berpengaruh secara positif dan signifikan terhadap kepuasan konsumen.

2. Kualitas makanan berpengaruh secara positif dan signifikan terhadap kepuasan konsumen.

3. Citra merek berpengaruh secara positif dan signifikan terhadap kepuasan konsumen.

4. Kepuasan konsumen sebagai mediator berpengaruh secara signifikan pada minat pembelian kembali.

\section{Saran}

Berdasarkan dari data peneliti, maka peneliti memberi saran dan juga penelitian selanjutnya sebagai berikut:

Bagi pihak restoran "XYZ"

Dari kesimpulan di atas, terdapat 3 variabel yang berpengaruh secara positif dan signifikan terhadap kepuasan konsumen, yang di mana sebagai mediator mampu mempengaruhi minat 
beli ulang di restoran "XYZ" Surabaya. Keamanan pangan merupakan variabel yang paling dominan perngaruhnya terhadap kepuasan konsumen. Perlu menjadi pengingat, bahwa agar tidak terjadi kasus keracunan makanan seperti yang pernah terjadi, adalah penting untuk senantiasa menjaga keamanan pangan. Variabel yang mendominas kedua adalah citra merek yang harus selalu dipertahankan dengan semakin gencar melakukan pendidikan akan pentingnya mengkonsumsi makanan sehat melalui setiap kanal pemasaran yang dimiliki oleh restoran "XYZ". Sehingga mampu menciptakan komunitas yang sadar akan pentingnya makanan sehat untuk semua kalangan.

\section{Untuk penelitian selanjutnya}

Pada penelitian selanjutnya dapat meneliti variable independent lainnya atau dari variable penting lainnya seperti kemasan, lokasi, kualitas layanan atau promosi.

\section{DAFTAR REFERENSI}

Aaker, D. A., \& Biel, A. L. (2009). Brand Equity and Advertising: Advertising Role in Building Strong Brand. Psychology Press.

Al-Tit, A. (2015). The effect of service and food quality on customer satisfaction and hence customer retention. Asian social science, 11(23), 129-139.

Andrenani, F., Taniaji, T. L., \& Puspitasari, R. N. M. (2012). The impact of brand image towards loyalty with satisfaction as a mediator in McDonald's. Jurnal manajemen dan kewirausahaan, 14(1), 64-71

Atkins, P., \& Bowler, I. (2001). Food quality. In Atkins, P., \& Bowler, I, Food in society: Economy, culture, geography. London, England: Amold.

Fungai, M. (2017). Factors Influencing Customer Repurchase Intentionin The Fast. Business \& Social Sciences Journal.

Herfangsyah, D. D., \& Handoko, D. W. (2015). Harapan dan Persepsi Konsumen pada Penerapan Keamanan Pangan di Restoran Jamoo Hotel Sangri-La Surabaya. Program Manajemen Perhotelan, Fakultas Ekonomi, Universitas Kristen Petra.

Kock, N., \& Hadaya, P. (2018). Minimum sample size estimation in PLS-SEM: The inverse square root and gamma-exponential methods. Information Systems Journal, 28(1), 227-261.
Kumar, S., \& Bhatnagar, D. D. (2017). Factors Affecting Customer Satisfaction of Food and Beverage Outlets- A Study of Food and Beverage Outlets betweenAmritsar and Jalandhar. Amity Business School, Amity University Rajasthan, Jaipur, India.

Kusdyah, I. (2012). Persepsi Harga, Persepsi Merek, Persepsi Nilai, dan Keinginan Pembelian Ulang Jasa Clinic Kesehatan. STIE Asia Malang.

Lahap, J., Ramlib, N. S., Said, N. M., \& Radzid, S. M. (2016). A study of brand image towards customer's satisfaction in the malaysian hotel industry. Social and behavioral sciences, 224, 149157.

Péneau, S., Hoehn, E., Roth, H. R., Escher, F., \& Nuessli, J. (2006). Importance and consumer perception of freshness of apples. Food quality and preference, 17(1-2), 9-19.

Praxiom Research Group Limited. (2019, August 29). food safety management definitions - ISO 22000 2018. Retrieved from https://www.praxiom. com/iso-22000-definitions.htm

Mensah, I., \& Dei Mensah, R. (2018). Effects of Service Quality and Customer Satisfaction on Repurchase Intention in Restaurants on University of Cape Coast Campus. Journal of Tourism, Heritage \& Services Marketing.

Murray, R., Glass-Kaastra, S., Gardhouse, C., Marshall, B., Ciampa, N., Franklin, K., Nesbitt, A. (2017). Canadian Consumer Food Safety Practices and Knowledge: Foodbook Study. Journal of Food Protection, 80(10), 1711-1718.

Namkung, Y., Jang, S., (2007), DPéneau, S., Hoehn, E., Roth, H.-R., Escher, F., and Nuessli, J. (2006). Importance and consumer perception of freshness of apples. Food Quality and Preference, Vol.17, No.1/2, pp. 9-19.

Rozekhi, N. A., Hussin, S., Siddiqe, A. S., Rashid, P. D., \& Salmi, N. S. (2016). The Influence of Food Quality on Customer Satisfaction in Fine Dining Restaurant: Case in Penang. International Academic Research Journal of Business and Technology.

Ryu, K., Lee, H., \& Kim, W. G. (2012). The influence of the quality of the physical environment, food, and service on restaurant image, customer perceived value, customer satisfaction, and behavioral intentions. International Journal of Contemporary Hospitality Management, 24(2), 200223.

Sentoso, F. (2019). Pengaruh Kualitas Makanan dan Persepsi Harga terhadap Keputusan Pembelian Kembali melalui Kepuasan Pelanggan Crunchaus di Pakuwon Mall Surabaya. Program Manajemen Bisnis, Program Studi Manajemen Fakultas Bisnis dan Ekonomi Universitas Kristen Petra. 
Srivastava, K., \& K. Sharma, N. (2013). Service Quality, Corporate Brand Image, and Switching Behavior: The Mediating Role of Customer Satisfaction and Repurchase Intention. Services Marketing Quarterly.

Teixeria, S., \& Sampaio, P. (2013). Food safety management system implementation and certification: survey result. Industrial Engineering Research Conference.

Tong, C., \& Wong, A. (2014). The Influences of Corporate Social Responsibility to Customer Repurchases Intentions, Customer Word-ofMouth Intentionsand Customer Perceived Food
Quality of Fast-Food Restaurants in Hong Kong and the Mediating Effects of Corporate Reputation. British Journal of Economics, Management \& Trade.

Wijayanto. (2019a, 04 4). radar surabaya. Retrieved from Radar Surabaya: https://radarsurabaya. jawapos.com/read/2019/04/04/129627/konsums $i$-salad-greenly-puluhan-orang-keracunandirawat-di-rs

Wijayanto. (2019b, 04 4). radar surabaya. Retrieved from Radar Surabaya: https://radarsurabaya. jawapos.com/read/2019/12/02/168222/greenlymakan-makanan-sehat-adalah-hak-semиaorang. 